\title{
Diagnostic and Measurement System for Marine Engines
}

\author{
ADAM CHARCHALIS \\ Marine Maintenance Department \\ Gdynia Maritime University \\ 81-225 Gdynia, Morska 81-87 \\ POLAND
}

\begin{abstract}
Modern way of machines' exploitation, due to their high level of structural complication, requires proper level of supervising. This is enabled by more than 60 years' development of the inspection and maintenance technologies. Nowadays it focuses on preventing the unplanned accidents by detection of prefailure states and predictive a future trend of the machine. To detect the problem and avoid the failure very important and essential is to develop the Non Destructive Testing (NDT) and Condition Monitoring including assessment of working process, vibration analysis, oil purity testing, endoscopic, ultrasonic and thermal analysis. The paper presents a design and structure of the Exploitation Decision Aid System dedicated for diagnosis of marine engines condition. There are also presented examples of results obtained with use of the system.
\end{abstract}

Key-Words: - Diesel engine, diagnostics, roughness, monitoring, vessel power plants

Received: May 3, 2020. Revised: August 27, 2020. Accepted: September 5, 2020. Published: September 9, 2020.

\section{Introduction}

Maritime industry, today, focuses largely on having minimal shipboard failures, defects or breakdowns. On ships that employ a limited crew, time management, utilizing available resources and prioritising important tasks is imperative to the proper functioning of the vessel. Condition Based Monitoring makes the job even simpler since the task is carried out with minimal intervention while the machinery is in its normal operating mode. Thus, essential is to develop the Condition Monitoring System including analysis of engine working process, vibration analysis, oil analysis, endoscopic, ultrasonic and thermal analysis which enables controlling of actual condition of equipment when it is 'in-service'. Contemporary ship's power plant is a very complex system consisting of a series of engines, machines and devices, frequently automated, which requires exploitation supervision by highly qualified staff. The STCW convention requires that a considerable part of the training in the field of exploitation of ship's power plants be performed with the use of simulators.

Exploitation knowledge is essential for the construction of simulators that should imitate reality as faithfully as possible. The exploitation knowledge can be grouped in the following ways:

- experts' knowledge

- analysis of documented damages and breakdowns

- use of measuring-registering systems designed for diagnostics.
In this paper the acquisition of exploitation knowledge is presented taking as an example a system of diagnostics of ships engines.

\section{Description of the measurement and diagnostic system}

The power of modern internal combustion engines which are used as ships' main propulsion is up to $90 \mathrm{MW}$. The power of turbine engines, mainly used on passenger ships, is over $30 \mathrm{MW}$, and in case of propulsion sets it is over $60 \mathrm{MW}$. On ships, next to the main engines there are also power generating sets and a range of auxiliary equipment. Marine power plant and propulsion system is a complicated mechanical system which requires using high efficiently and reliable machines. Moreover, such complex system requires properly educated and experienced maintenance personnel, who, equipped with Maintenance System, will ensure safe ship operating in various conditions. Therefore, in Gdynia Maritime University special attention is paid to practical classes preparing future engineer officers for detecting symptoms of failures in engines systems and assessing their appropriate work by analysing operating parameters. For internal combustion engines it can be done by proper analysis of indicator diagrams, i.e. analysis of pressure distribution in engine cylinders as a function of crankshaft angle. It is enabled thanks to modernized laboratory station of turbocharged engine 3AL 25/30 Cegielski Sulzer. 


\subsection{The engine 3AL 25/30}

Main technical particulars of the engine are:

$\begin{array}{lll}\text { - } & \text { type } & -3 \text { AL 25/30 } \\ \text { - } & \text { no. of cylinders } & -3 \\ \text { - } & \text { bore }[\mathrm{mm}] & -250 \\ \text { - } & \text { stroke }[\mathrm{mm}] & -300 \\ \text { - } & \text { swept capacity }\left[\mathrm{cm}^{3}\right] & -14726 \\ \text { - } & \text { power rate }[\mathrm{kW}] & -408 \\ \text { - } & \text { rotational speed }[\mathrm{rpm}] & -750 \\ \text { - } & \text { compression ratio } & -1: 13\end{array}$

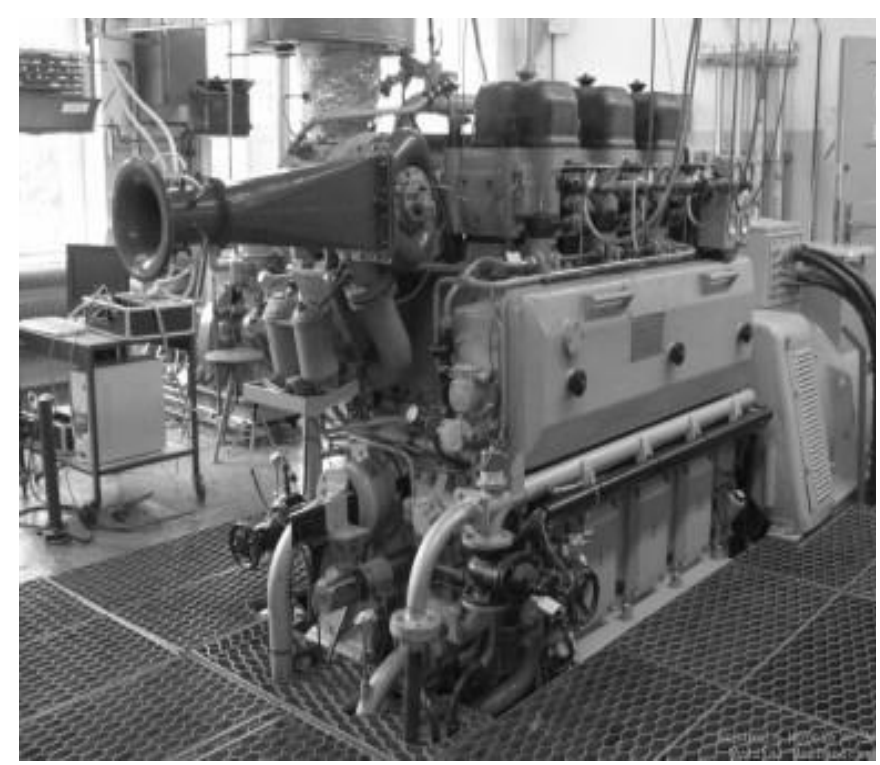

Fig. 1. Marine engine 3AL 25/30

The engine instrumentation allows for simulating fuel installation malfunctions. Simulation of leakage can be done by adjustment of drain screw installed at high pressure fuel pump at $2^{\text {nd }}$ cylinder. Simulation of injection faults is possible thanks to specially prepared injecting valves with partly clogged or enlarged sprayer holes.

\subsection{EMOS - operating station}

All parameters controlled by operating station are available for outer recorders.

The main tasks of EMOS are:

* operator access to all controlled working parameters,

* constant display of alarms list with alarm on, alarm off and acknowledge time,

* acknowledgement of appearing alarms using the keyboard or the mouse,

* possibility of setting four alarm threshold levels for analog signals,

* possibility of setting time delays of alarm signals,
* changing of configuration of measurement channels, selection of measurement ranges and calibration,

* constant archiving of data and simple mode of files outlook,

* recording of trends of analog data and trends of changes based on records history,

* data export to outer receivers for subsequent analysis and processing,

* printing of the rapports and data sets,

* independent work of two monitors enabling display of two pictures in the same time.

In the case of occurring the alarm, EMOS system initiates visual alarm in the form of a blinking light and a horn acoustic signal. The alarm initiation delay can be set on individual determined for every alarm channel $[3,4]$.

Measurement systems of the engine, which include a measuring orifice for the flow of air supply, a fuel consumption meter, manometers, thermometers, installed at all nodes of the engine installations and stationary indicator Unitest 2008, enable a full analysis of the heat balance and an assessment of the engine's working process $[6,7]$.

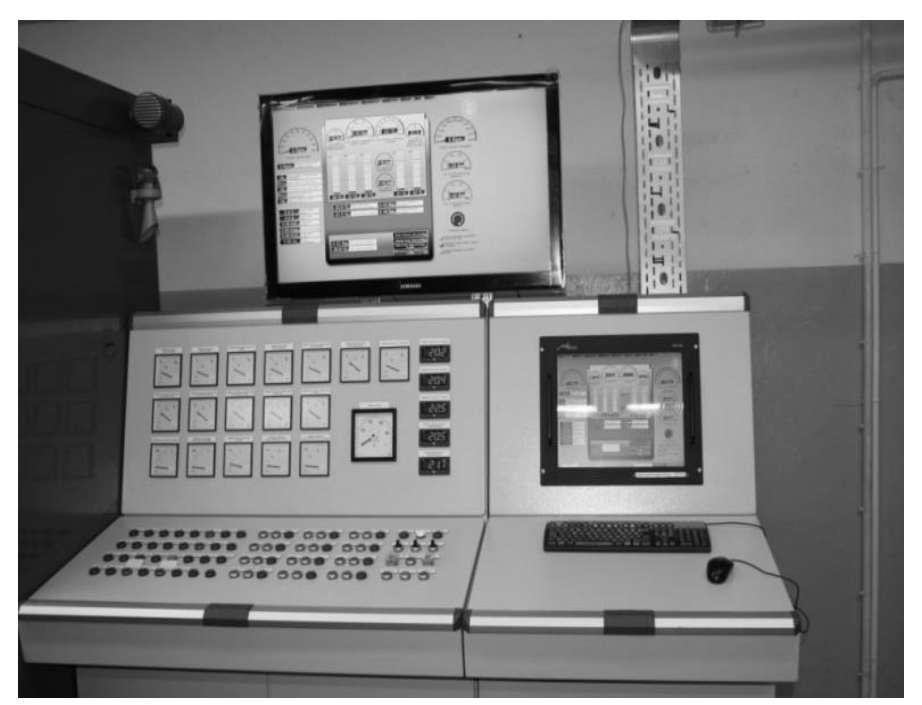

Fig. 2. General view of operating station EMOS

For measurement of variable pressure in cylinders and high pressure fuel pipes electronic indicator Unitest can be used. It enables analysis of indicator diagrams obtained during simulations of failures frequently occurred in exploitation, like failures of fuel pumps (leakage), injectors (pressure at the beginning of injection, damage of compression spring), damages in charging system (contamination of the compressor or turbine) and in set of the piston, piston rings and cylinder. 


\subsection{Electronic indicator Unitest 2008}

The station of Unitest 2008 indicator is equipped with sensors of pressure in cylinder (Kistler type 6353A24) and in high pressure fuel pipes (Optrand AutoPSI-S-2000) mounted in all cylinders, sensor of crankshaft angle with TDC marker, analog-digital transducers and a personal computer.

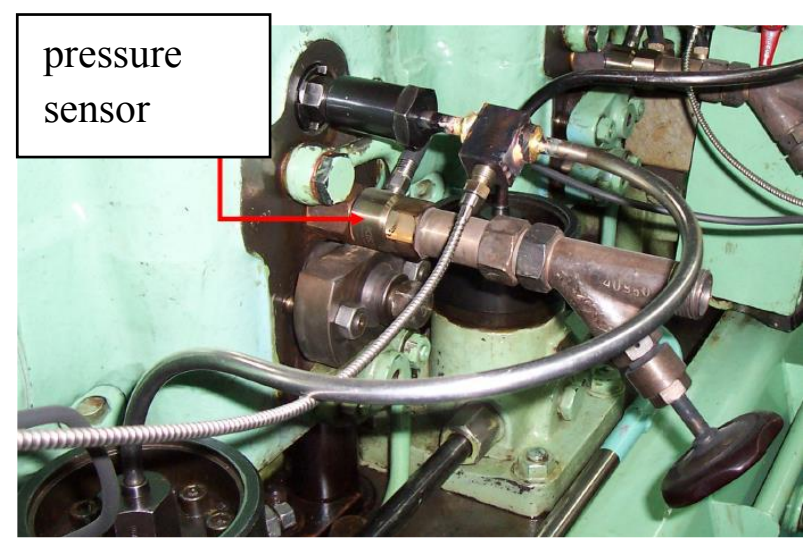

Fig. 3. Indicator cock with in-cyliner installed gas pressure sensor

Example of a screen window presenting combustion and injection pressure charts can be seen in Fig. 4.

Extension of selected parts of a picture is possible, and run of functions can be related to mean values of all cylinders and values of reference. Apart from graphic analysis of runs, automatically following parameters of combustion and injection are determined:

* indicated power of the engine;

* mean indicated pressure;

* peak of combustion pressure;

* angle of combustion pressure peak;

* expansion pressure (at angle $36^{\circ}$ after TDC);

* peak injection pressure;

* angle of injection pressure peak.

Indicator diagrams seem to have great potential for injection systems diagnosis $[12,13]$. Due to the significant, in recent times, the fall in prices of electronic indicators, they are increasingly become a standard measuring equipment of marine engines. Despite the availability of, and significant progress in the field of equipment and measurement techniques of indicated pressure, there is no significant progress in the field of analysis and diagnostic use of the obtained pressure curves. Obtaining reliable diagnostic information based on the indicator diagram is an important research challenge.

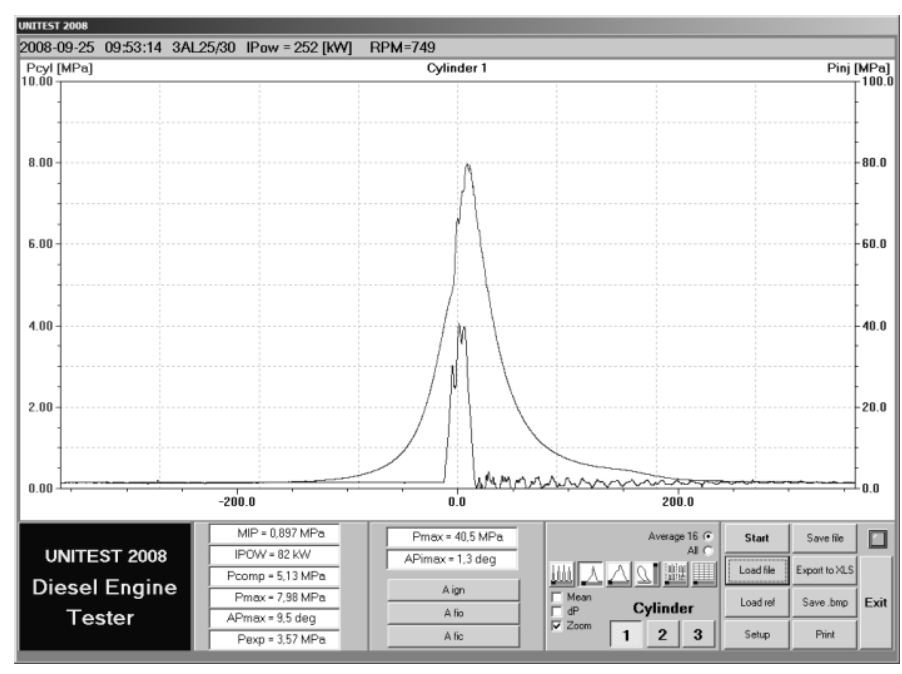

Fig. 4. Electronic indicator program window

A visible symptom of the simulated injection pump leakage is the decline in mean indicated pressure and the accompanying decline in the value of the maximum combustion pressure (Fig. 5).

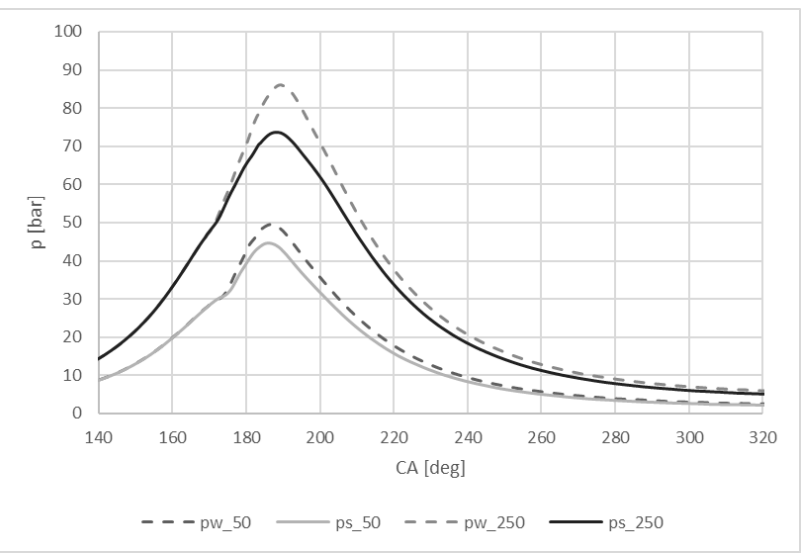

Fig. 5. Comparison of the indicator diagram for the reference state (pw50; pw250) and the simulation of fuel pump leakage (ps50; ps250) for engine power $50 \mathrm{~kW}$ and $250 \mathrm{~kW}$

It seems that the significant improvement in the diagnostic use of the indicator diagram can be obtained by designating the heat release characteristics. The purpose of the article was to evaluate the potential for the use of heat release characteristics to evaluate the technical condition of the fuel pumps of marine diesel engines.

Example of net heat release rate analysis, is shown in Fig. 6. A significant reduction in the amplitude of the net heat release rate $\mathrm{q}$ for the load of $250 \mathrm{~kW}$ was observed $[11,14]$. 


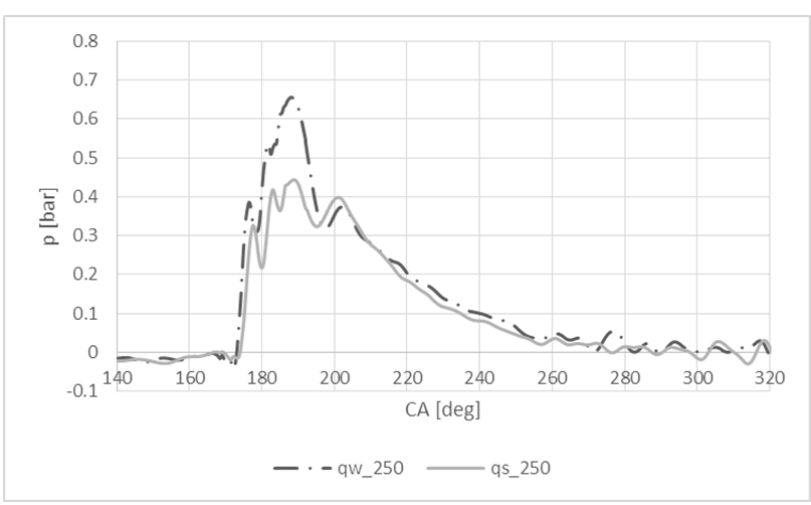

Fig. 6. Comparison of the net heat release rate $q$ for the nominal state (qw250) and the state of clogged injector nozzles (qs250) for specific loads $250 \mathrm{~kW}$

\section{Technical Diagnostic Laboratory}

The essential for Measurement and Diagnostic System is apparatus of Technical Diagnostic Laboratory, described later:

* Mobile Gas Analyzer by Testo,

* Vibration analyzer by Brüel \& Kjaer, and software PULSE,

* Electronic indicator Unitest 2008,

* Industrial Video endoscope XLG3 by Everest,

* Acoustic Emission Set by Vallen System,

* Thermo vision Camera by NEC Avio Co.,Ltd.,

* Spectrometer Spectroil Q100,

* Analyzer/Recorder of working process by Sefram Instrumens \& Systems.

\subsection{Using vibroacoustic devices for diagnosing of shafts misalignment}

Usual measurement methods of coaxiality parameters of the propulsion system require disassembling protection covers of shafting between engines and reduction gears. Application of vibroacoustic diagnostics to technical maintenance makes possible to decrease operational cost of the vessel by basing its operational on its actual technical state and predicted failure states [1]. In paper [1] it was assumed that determination of a relationship between the coaxiality parameters and changes of the recorded vibration signals should bring about identification of the diagnostic model consisting in:

- choice of geometrical parameters describing the position deviations, i.e. axis slope and displacement;

- choice of adequate parameters of the vibroacoustic signal;
- determination of a mutual relationships between sets of the coaxiality deviations and vibration diagnostic parameter values;

- sensitivity assessment of the symptoms in question;

- establishing the database for statistical analysis and operational decision making.

The research in question was limited to control of the axis slope only. This assumption was made to account for influence of the displacement hull deflection. In this case the axis displacements are controlled solely during assembling the shafting system in the production and repair stages. The energy emitted in result of a change of technical state of the flange connection was assumed to be reflected in the recorded vibration signal.

For realisation of the investigations the measurement instruments: 3050-A-60, the module LAN-XI $51.2 \mathrm{kHz}$ (CCLD, V) analyser and PULSE v 9.0 software of Bruel \& Kjaer, were used making possible to collect and process measured data.

\subsection{Examination of oil impurities}

The state of pollution of lubricating oil of engines and gears is a very important source of diagnostic information. As a result of the examination can be elaborated the methodology of evaluation of changes trends of the level of oil pollution as a result of wear of the engine. That is why, apart from the standard, periodical analysis of oil, the examination of oil is carried out to analyse impurities - also metallic - with the use of spectrometer analysis. In Fig. 7 spectrometer Spectroil Q100 is presented. It enables identification of 22 metallic elements presented in oil as a result of wear process. Based on the percentage content of these elements and material composition of the engine components it is possible to assess the degree of degradation of a given element.

It is also possible to assess, by using the trend analysis, the dynamics of changes and in nondisassembly diagnostics determine the operating limit state and the need to replace a part or subassembly.

Moreover, the spectrometer enable detection in oil of 10 non-metallic elements influencing on lubricating properties of oil. Hence, it is possible to operate engine oil according to its condition instead of operating time. Compared to other methods, e.g. radioisotopic, oil testing for the content of various elements has the advantage that is quick and requires very little oil for testing. 


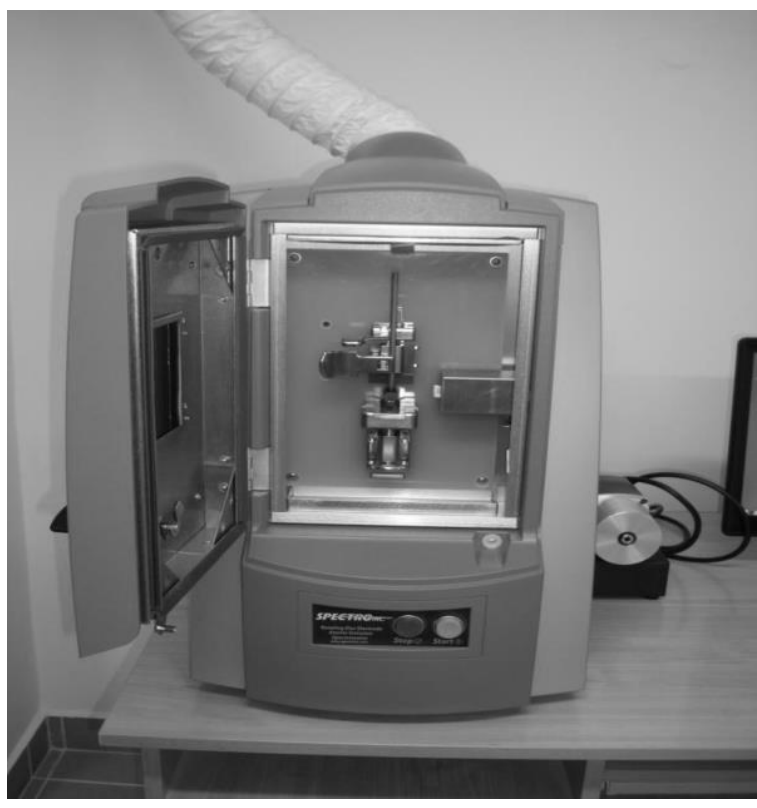

Fig. 7. General view of spectrometer Spectroil Q100

\subsection{Video endoscope research}

Endoscopic methods are hardly developed in medicine and exploitation of rotating machinery, i.e. turbine engines in aeroplanes or ships. The exploitation of the aeroplane turbine engines JT6D proved that over $50 \%$ exploitation breakdowns is discovered as a result of endoscopic examination.

The inner examination can be carried out throughout observational and technological apertures of a diameter larger than $8,4 \mathrm{~mm}$. Endoscopic testing are very useful in assessing the technical condition of internal parts of machine and devices like:

- flow part of compressors, combustion chambers and turbines of turbine engines,

- combustion chambers, valves, piston rings of piston engines,

- $\quad$ pipelines, coolers, tanks, e.g. pressure tanks.

Video endoscope presented in Fig. 8. enables visualization at LCD display, video recording, measuring different failures and evaluation of technical condition of internal spaces.

3D phase measurement enables inspection and measurement of defects by only one lens, what eliminate necessity of its replacing by measurement lens. It lets scanning and carry measurement in 3 dimensions of every detected discontinuity.

Figure 9 presents typical damages of gas turbine blades found by endoscopic methods.

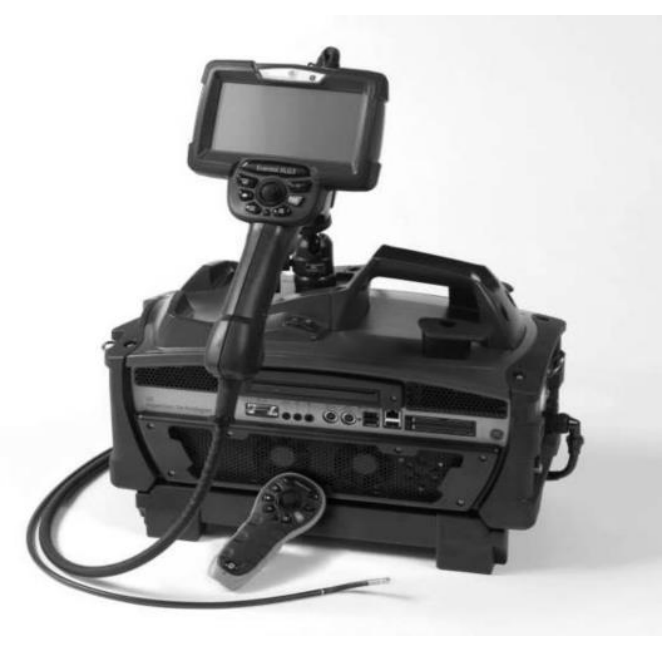

Fig.8. Video endoscope XLG3 Everest9
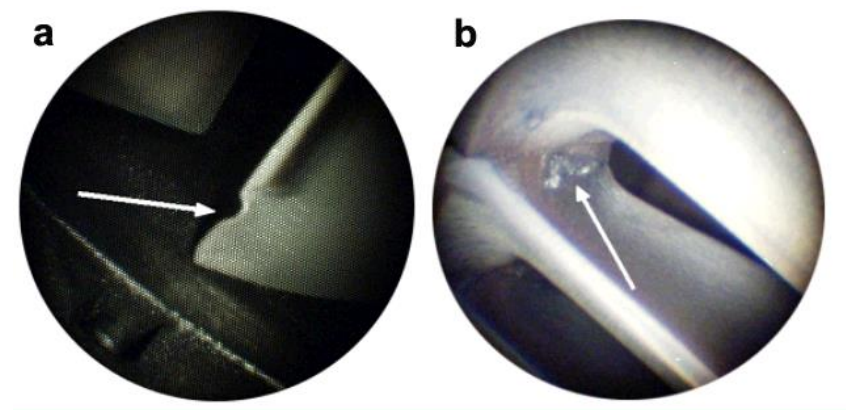

Fig. 9. Endoscopic picture of failures of elements of turbine engine flow part: a) dent of the edge of the compressor blade, b) erosive loss of the space between the scapula

\subsection{Thermovision research}

Thermo-visual systems are widely used in industry diagnostics for wall thermal insulation identification, for electric wire examination, crack detection in machine heating or cooling components and for heat distribution determination in electronic instruments. It is also used as a 'predictive' maintenance tool for ships power plants. Checking temperatures of engine room components is everyday duty of each watch keeping engineer. Among others methods thermovision can be used. IR thermography has the ability to identify problems before they occur. It is especially helpful for trouble shooting potential electrical overloads, worn or bad circuit breakers and buses. IR thermography can also be used to detect bad bearings, shafts, worn pulleys or any application where heat detection would be beneficial $[10,15]$. 
Thermographic camera makes the control process easier, faster, more precise and not dependent on the distance and access.

The FLIR E95 portable thermo-visual camera can work in 3 temperatures ranges: $-20^{\circ} \mathrm{C}$ to $120^{\circ} \mathrm{C}$, $0^{\circ} \mathrm{C}$ to $650^{\circ} \mathrm{C}$ and $300^{\circ} \mathrm{C}$ up to $1950^{\circ} \mathrm{C}$. Figure 10 presents surface of turbocharger of laboratory engine.

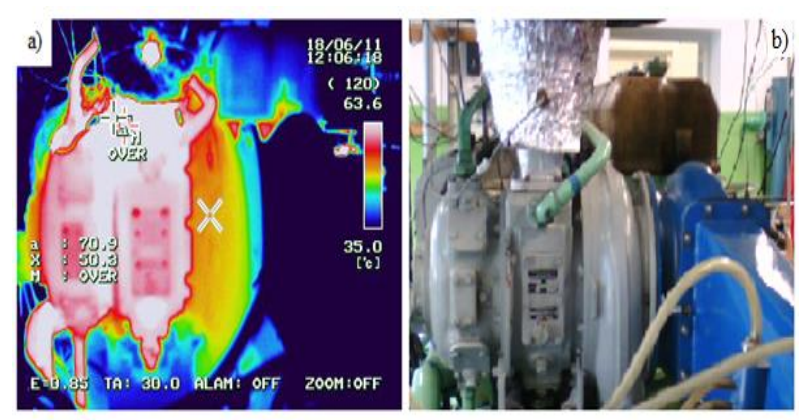

Fig. 10. Thermogram (a) and visible picture (b) of turbocharger of laboratory engine 3 AL 25/30 N=195 kW [9]

\subsection{PAC acoustic emission measurement method unit}

EA signal is generated in materials and on their surface as a result of mechanical loads. It is caused by physical processes taking place in these materials [1]. The reason for the occurrence of EA may be plastic deformation of the material, cracking, corrosion, phase or structural changes, leaks. The EA measurement set consists of a sensor, preamplifier, recorder, etc. (Fig. 11). The unit is connected to the PC by means of USB and does not require any extra power supply, which is vital while operating outside. The set is provided with dedicated software for data recording and analysis.

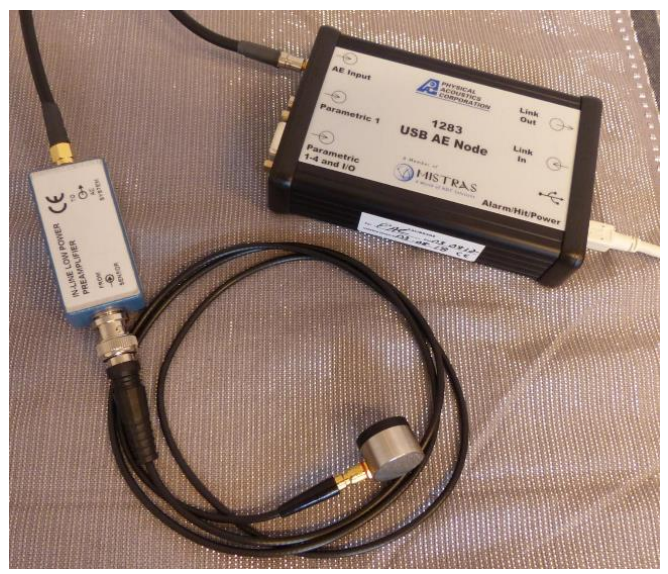

Fig. 11. Set of acoustic emission PAC
The set allows for destruction and disassemblyfree measurements of machine components wear; the components like fuel injectors, water hydraulic pumps, hull plating and piping, which are exposed to strains, deformations and loads [8].

Acoustic emission method (AE) can be used for the diagnosis of machine parts such as, for example: fuel injectors, valves, tanks, installation, etc. This paper presents the research results of monitoring of compressed air starting system of 3AL25/30 engine placed in Maritime Engineering Faculty of Gdynia Maritime University. During the study recorded a number of signal parameters e.g.: amplitude, number of events - hits, energy, RMS, frequency.

Example of graph showing the amplitude and average frequency of the signal as a function of time, recorded during the study is presented in Fig. 12.

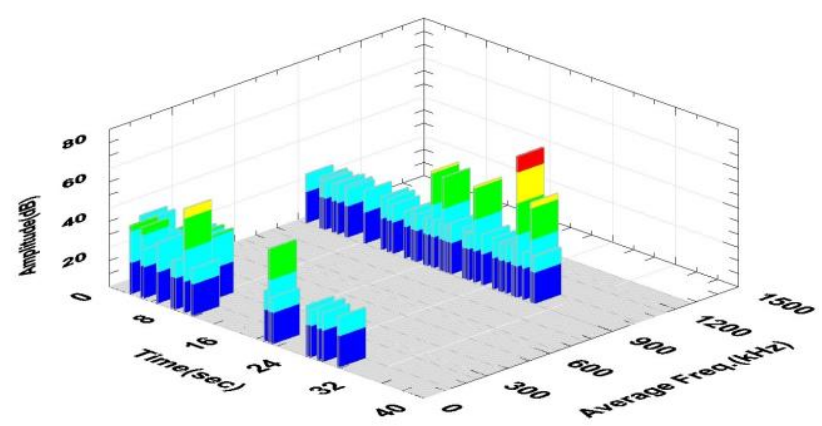

Fig. 12. An example of chart showing AE signal during leakage in tested installation

Analysis of recorded parameters revealed leakage in the installation - damage of one of the valves.

The test results indicate that the AE method can be useful for monitoring the technical condition of pressure systems of engines and devices in a ship's engine room during normal operation as an on-line system.

\section{Conclusion}

- Application of the proposed approach makes managing the engine's operation time much more rational, especially at its end.

- The proposed approach is non-invasive and does not require taking the ships out of service.

- Realisation of investigations of the kind makes it possible to collect data for a database of the monitoring system of ships wich is expected to improve their operational features.

- Experience gained during the investigations would be utilised for other power plants. 
- Presented method is enough sensitive in operation of propulsion plant that it enables to find primary symptoms of changes technical state of engines

\section{References:}

[1] Baran I., Nowak M., Schmidt J., Ono K., Potentials of AE Application in Testing Industrial Pipelines, Advances in Acoustic Emission, USA, 2007.

[2] Charchalis A., Complex Measurement System for Enhancement of Capability for Marine Engines Diagnostics, Journal of TransNav, Vol. 7, No. 3, 2013, pp. 415-420.

[3] Charchalis A., Conditions of Drive and Diagnostic Measurements During Sea Tests, Journal of Kones Powertrain and Transport, Vol. 13, No. 4, 2006, pp. 271-277.

[4] Charchalis A., Diagnostic and Measurement System for Marine Engines, Journal of Kones Powertrain and Transport, Vol. 19, No. 1, 2012, pp. 35-40.

[5] Charchalis A., Diagnostics System of Marine Engines and Auxiliary Machinery, Journal of KONBIN, Vol. 24, No. 4, 2012, pp. 25-32.

[6] Charchalis A., Szyfelbain M., New Methods of Marine Power Plant Diagnostics, Journal of Kones Powertrain and Transport, Vol. 25, No. 1, 2018, pp. 35-40.

[7] Dereszewski M., Charchalis A., Polanowski S., Evaluation of Diagnostic Information about Marine Engine Work Based on Measurement of the Angular Speed Discrete Value, Journal of Kones Powertrain and Transport, Vol. 19, No. 2, 2012, pp.121-128.

[8] Dudzik K., The Possibility of Application Acoustic Emission Method for Controlling Friction Stir Welding of AW-5083 Aluminium Alloy Sheets, In Proc.of 26th International Conference on Metallurgy and Materials. Ostrava, Czech Republic, 2017, pp.1695-1700.

[9] Molenda J., Charchalis A., Preliminary Research of Possibility of Using Thermovision for Diagnosis and Predictive Maintenance of Marine Engines, Journal of KONBiN, Vol. 49, No. 3, 2019, pp. 49-56.

[10] Pasagic V., Muzevic M., Kelenc D., Infrared Thermography in Marine Applications, Brodogradnja/Shipbuilding, Vol. 59, No. 2, 2008, pp. 123-130.

[11] Pawletko R., Polanowski S., Influence of TDC Determination Methods on Mean Indicated Pressure Errors in Marine Diesel Engines,
Journal of Kones Powertrain and Transport, Vol. 18, No. 2, 2011, pp. 355-364.

[12] Pawletko R., Polanowski S., Research of the Influence of Marine Diesel Engine Sulzer AL 25/30 Load on the TDC Position on the Indication Graph, Journal of Kones Powertrain and Transport, Vol. 17, No. 3, 2010, pp. 361368.

[13] Polanowski S., Pawletko R., Acquisition of Diagnostic Information from the Indicator Diagrams of Marine Engines Using the Electronic Indicators, Journal of Kones Powertrain and Transport, Vol. 18, No. 3, 2011, pp. 359-366.

[14] Polanowski S., Pawletko R., Application of Multiple Moving Approximation with Polynomials in Curve Smoothing, Journal of Kones Powertrain and Transport, Vol. 17, No. 2, 2010, pp. 395-402.

[15] Singh B., Can Effective Predictive Maintenance Be More Beneficial on Board Ships? Marine Insight (updated April 2019), https://www.marineinsight.com/tech/predictive -maintenance-on-board-ships/.

\section{Creative Commons Attribution License 4.0 (Attribution 4.0 International, CC BY 4.0)}

This article is published under the terms of the Creative Commons Attribution License 4.0 https://creativecommons.org/licenses/by/4.0/deed.en_US 